\title{
Leveraging household survey data to measure barriers to health services access in the Americas
}

\author{
Ernesto Báscolo, ${ }^{1}$ Natalia Houghton, ${ }^{1}$ and Amalia Del Riego ${ }^{1}$
}

Suggested citation Báscolo E, Houghton N, Del Riego A. Leveraging household survey data to measure barriers to health services access in the Americas. Rev Panam Salud Publica. 2020;44:e100. https://doi.org/10.26633/RPSP.2020.100

ABSTRACT Objective. To identify advantages and challenges of using household survey data to measure access barriers to health services in the Americas and to report findings from most recent surveys.

Methods. Descriptive cross-sectional study using data retrieved from publicly available nationally representative household surveys carried out in 27 countries of the Americas. Values for indicators of access barriers for forgone care were generated using available datasets and reports from the countries. Results were disaggregated by wealth quintiles according to income or asset-based wealth levels.

Results. Most surveys were similar in general approach and in the categories of their content. However, country-specific questionnaires varied by country, which hindered cross-country comparisons. On average, about one-third of people experienced multiple barriers to forgone appropriate care. There was great variability between countries in the experience of these barriers, although disparities were relatively consistent across countries. People in the poorest wealth quintile were more likely to experience barriers related to acceptability issues, financial and geographic access, and availability of resources.

Conclusions. The analysis indicates major inequalities by wealth status and uneven progress in multiple access barriers that hinder progress towards the goals of equity as part of the Sustainable Development Goals and universal health in the Americas. Access barriers were multiple, which highlights the need for integrated and multisectoral approaches to tackle them. Given the variability between instruments across countries, future efforts are needed to standardize questionnaires and improve data quality and availability for regional monitoring of access barriers.

Keywords Health services accessibility; universal health coverage; sustainable development; health care reform; Americas.

Universal access to health has been defined as "the absence of geographical, economic, sociocultural, organizational or gender barriers that prevent all people from having equitable use of comprehensive health services and living a healthy life that promotes their development and well-being" (1). This concept was first endorsed by Member States of the Pan American Health Organization (PAHO) in 2014 with the unanimous adoption of Resolution CD53.R14, Strategy for Universal Access to Health and Universal Health Coverage (1).
Governments in the Americas have further recognized the importance of communicating actionable data on progress towards reducing barriers to accessing health services. This commitment was recently demonstrated with the launching of the Regional Compact on Primary Health Care (PHC) for Universal Health, PHC 30-30-30, which aims to reduce access barriers to health by at least $30 \%$ by 2030 (2). A similar target for reducing access barriers was prioritized in PAHO's new Strategic Plan for 2020-2025 (3).

\footnotetext{
1 Pan American Health Organization/World Health Organization, Washington, DC, United States of America. $\bowtie$ Ernesto Báscolo, bascoloe@paho.org
} 
Monitoring progress towards reducing access barriers is particularly relevant as the Sustainable Development Goals (SDGs) pledge to 'leave no-one behind' has ensured that acting to reduce discrimination and inequities, including identifying who is being left behind and why, has risen on international and national agendas (4). Measuring intervention coverage (people using health services they need) together with access barriers, and inequalities in both, can provide a complete picture of who can use the health services they need and the specific reasons why care is not being accessed (5).

Despite this need, developing measurement approaches for monitoring access barriers poses several challenges. First, most studies on health access goals focus on analyzing intervention coverage indicators, which fail to capture those individuals who do not seek health services and the reasons why they are unable to do so (6). This slows progress as barriers to access remain undiagnosed (6). In addition, there is lack of representativeness as studies on access barriers are often part of primary empirical studies exploring initial contact and types of barriers related to specific health services or subpopulations $(7,8)$. Most of these studies are based on qualitative methods, including examples from Colombia, Brazil, and Peru $(9-14)$. Moreover, quantitative studies that analyze access barriers for the general population based on population surveys are almost nonexistent and are generally limited to high-income countries (15). There is one multicounty study in the Americas that adapted the Commonwealth Fund International Health Policy Survey to assess people's primary care experiences in six Latin American and Caribbean (LAC) countries $(15,16)$. This study measured key indicators on access barriers along the dimensions of availability, accommodation, and effective coverage. Following a similar approach, the global PHC Performance Initiative (PHCPI) tool reports on indicators that measure whether the population has effective, affordable, timely access to PHC facilities that are geographically convenient (17). There are a couple of cross-sectional studies based on existing household surveys that examined progress in trends and inequalities in access barriers in Colombia, El Salvador, Paraguay, and Peru $(18,19)$. A more recent regional study identified 23 access barriers indicators that can be derived from 49 household surveys from 31 countries of the Americas (20). Before implications for current practice can be drawn, more studies are needed to appraise the feasibility, quality, and comparability of these data for measuring access barriers.

In this context, this study contributes to the discussion by providing in-depth secondary data analyses of selected access barriers indicators and highlighting data advantages and limitations when using these indicators. The study outlines key indicators of access barriers that can be used to show average levels and inequalities on the path to the SDGs and universal health. These data can provide useful guidance to policymakers in identifying which segments of the population are being left behind and why. It should be noted, however, that this paper does not evaluate specific country's progress towards reducing access barriers or draw conclusions about the effectiveness of interventions that have been implemented in a country. Instead, country data are used to illustrate the performance of the indicators, synthesize lessons learned from measuring and monitoring access barriers in different contexts, and inform recommendations for the regional monitoring and measurement of access barriers. Furthermore, tracking progress towards universal health requires simultaneous monitoring of indicators that measure health sector inputs, outputs, and impacts, with an equity focus (21).

\section{METHODS}

\section{Study design and data sources}

This descriptive cross-sectional study used data retrieved from publicly available nationally representative household surveys carried out in 27 countries of the Americas, including the Demographic Health Survey (DHS), the Multiple Indicator Cluster Surveys (MICS), and country household surveys based on the Living Standards Measurement Study (LSMS) model (Table 1). These countries were selected because they each have at least two recent DHS, MICS or LSMS-type surveys. Datasets that had information only prior to the year 2000 were excluded from the analysis.

All surveys used multi-stage cluster sampling designs to obtain nationally representative data. DHS and MICS standardized questionnaires were used to collect information from women of reproductive age living in the sampled households. LSMS-type surveys collected information on living conditions from all members of the sampled households, including health status, education, employment, and income. All surveys were implemented by national census or statistics agencies. Ethical approval was the responsibility of the institutions in charge of each survey. All analyses relied on publicly available, anonymized datasets.

\section{Study variables}

The choice of access barriers measures in this analysis was based on the conceptual dimensions and indicators previously identified from household surveys in the Americas (20). The first indicator measured unmet need through forgone care expressed as the share of individuals that had a healthcare need but do not consult an "appropriate" provider, or do not consult at all, due to any reason. The following measures captured reasons for forgone appropriate care and included indicators related to each dimension of the access barriers metric previously described (20); namely, availability, geographic accessibility, financial accessibility, accommodation, acceptability, contact, and effective coverage. This study also examined forgone care for common childhood illnesses, i.e. acute respiratory infections (ARI) and acute diarrheal diseases (ADD). The full description of dimensions and indicators are presented in Table 2.

Study variables were determined by asking individuals about perceived health needs and related behavior in the $3-12$ months prior to the survey, i.e., whether or not the individual had sought appropriate health services, or not sought at all, and reasons behind their decision. The following questions (with variations among surveys) were studied:

- In the last 30 days have you had any illness or accident? Possible answers: Yes / No / Does not know. 
TABLE 1. Countries with existing household surveys since 2000 , by dataset and source, used to analyze barriers to accessing health services in the Americas

\begin{tabular}{|c|c|c|c|}
\hline Country & Health system taxonomy ${ }^{a}$ & Datasets & Source (website) \\
\hline Argentina & Social insurance model & - 2011-12 MICS report and dataset & - UNICEF \\
\hline Barbados & National health service & - 2016 Barbados Survey of Living Conditions (BSLC) & - IDB \\
\hline Belize & National health service & - 2015-16 MICS report and dataset & - UNICEF \\
\hline Bolivia & National health service & - 2003 and 2008 DHS reports and datasets & - The DHS Program \\
\hline Chile & Social insurance model & $\begin{array}{l}2017 \text { Encuesta de Caracterización Socioeconómica } \\
\text { Nacional (Casen) }\end{array}$ & - Ministerio de Desarrollo Social y Familia \\
\hline Canada & National health insurance & - 2018 Canadian Community Health Survey (CCHS) & - Health Canada \\
\hline Colombia & Social insurance model & $\begin{array}{l}\text { - } 2018 \text { Encuesta Nacional de Calidad de Vida (ECV) } \\
\text { - } 2015 \text { DHS report and dataset }\end{array}$ & $\begin{array}{l}\text { - Departamento Administrativo Nacional de Estadística } \\
\text { (DANE) } \\
\text { - The DHS Program }\end{array}$ \\
\hline Costa Rica & Social insurance model & $\begin{array}{l}\text { - } 2006 \text { Encuesta Nacional de Salud en Costa Rica } \\
\text { (ENSA) }\end{array}$ & - Centro Centroamericano de Población \\
\hline Ecuador & National health service & - 2013-14 Encuesta de Condiciones de Vida (ECV) & - Instituto Nacional de Estadística y Censos \\
\hline El Salvador & National health service & $\begin{array}{l}2018 \text { Encuesta de Hogares de Propósitos Múltiple } \\
\text { (EHPM) }\end{array}$ & $\begin{array}{l}\text { - Dirección General de Estadística y Censos } \\
\text { (DIGESTYC) }\end{array}$ \\
\hline United States & Private insurance system & - 2018 Medical Expenditure Panel Survey (MEPS) & - Agency of Healthcare Research and Quality (AHRQ) \\
\hline Guatemala & National health service & $\begin{array}{l}\text { - } 2014 \text { Encuesta Nacional de Condiciones de Vida } \\
\text { (ENCOVI) } \\
\text { - } 2014 \text { DHS report and dataset }\end{array}$ & $\begin{array}{l}\text { - Instituto Nacional de Estadística Guatemala (INE) } \\
\text { - The DHS Program }\end{array}$ \\
\hline Guyana & National health service & $\begin{array}{l}\text { - } 2014 \text { MICS report and dataset } \\
\text { - } 2009 \text { DHS report and dataset }\end{array}$ & $\begin{array}{l}\text { - UNICEF } \\
\text { - The DHS Program }\end{array}$ \\
\hline Haiti & Out-of-pocket model & - 2016-17 DHS report and dataset & - The DHS Program \\
\hline Honduras & National health service & - 2011-12 DHS report and dataset & - The DHS Program \\
\hline Jamaica & National health service & - 2011 MICS report and dataset & - UNICEF \\
\hline Mexico & Social insurance model & $\begin{array}{l}2016 \text { Encuesta Nacional de Ingresos y Gastos de } \\
\text { los Hogares (ENIGH) }\end{array}$ & - Instituto Nacional de Estadística y Geografía (INEGI) \\
\hline Nicaragua & National health service & $\begin{array}{l}2001 \text { Encuesta Nicaraguaense de Demografia y } \\
\text { Salud (DHS) }\end{array}$ & $\begin{array}{l}\text { - Instituto Nacional de Información de Desarrollo } \\
\text { (INIDE) }\end{array}$ \\
\hline Panama & Social insurance model & - 2013 MICS report and dataset & - UNICEF \\
\hline Paraguay & National health service & - 2017 Encuesta Permanente de Hogares (EPH) & - Dirección General de Estadística, Encuestas y Censos \\
\hline Peru & Social insurance model & $\begin{array}{l}\text { - } 2018 \text { Encuesta Nacional de Hogares sobre } \\
\text { Condiciones de Vida y Pobreza (ENAHO) } \\
\text { - } 2014 \text { DHS report and dataset }\end{array}$ & $\begin{array}{l}\text { - Instituto Nacional de Estadística e Informática (INEI) } \\
\text { - The DHS Program }\end{array}$ \\
\hline Dominican Republic & Social insurance model & - 2013 DHS report and dataset & - The DHS Program \\
\hline Saint Lucia & National health service & - 2012 MICS report and dataset & - UNICEF \\
\hline Suriname & National health service & - 2018 MICS report and dataset & - UNICEF \\
\hline Trinidad \& Tobago & National health service & - 2011 MICS report and dataset & - UNICEF \\
\hline Uruguay & Social insurance model & $\begin{array}{l}\text { - } 2018 \text { Encuesta Continua de Hogares (ECH) } \\
\text { - 2012-13 MICS report and dataset }\end{array}$ & $\begin{array}{l}\text { - Instituto Nacional de Estadística (INE) } \\
\text { - UNICEF }\end{array}$ \\
\hline Venezuela & National health service & - 2000 MICS report and dataset & - UNICEF \\
\hline
\end{tabular}

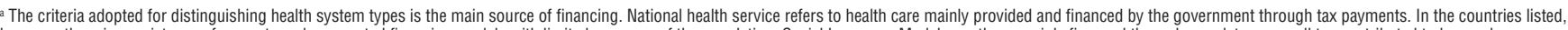
however, there is coexistence of separate and segmented financing models with limited coverage of the population. Social Insurance Models are those mainly financed through mandatory payroll tax contributed to by employers, employees, or both. In the National Health Insurance Model, payment comes from a government-run insurance program that every citizen pays into. In the out-of-pocket model individuals rely on care provided by non-profit organizations, private policies they can purchase themselves or they go without coverage at all. All other insurance schemes that are predominantly financed through private premiums are defined as Private Insurance System. It is worth noting that countries in the Americas have mixed elements of all models. This is due to their fragmented nature and existence of separate systems for separate classes of people.

Source: Prepared by the authors from the sources listed.

If yes,

- Where did you go for care for this illness or accident?

Possible answers: Public Health Facility / Private Health

Clinic / Urgent Care / Pharmacy or self-medication / At

home / Home remedy / Did nothing / Other.

If you didn't visit an appropriate health facility or did nothing,

- What are the reasons you didn't go to a health facility?

Possible answers: Had no money / It's far away / Long waiting time / There are no medicines / There are no doctors / Don't trust doctors / It was not serious / It was not necessary /
Prefer to be cured with home remedies / Don't have insurance / Self-prescribed or repeated previous prescription / Lack of time / Abuse by health personnel / Other.

Appropriate care was defined as situations when individuals sought care from any qualified medical professional in government health facilities and private hospitals/clinics during illnesses or accident. Other types of care, such as purchasing medicines from pharmacy, home remedies, and visiting pharmacies, temples, or traditional healers were defined as inappropriate care. To include only perceived health care needs, 
TABLE 2. Indicators used to analyze health access barriers in the Americas, by dimensions of access

\begin{tabular}{|c|c|c|c|}
\hline \multirow[t]{3}{*}{ Dimension of access } & \multicolumn{3}{|c|}{ Unmet needs for health care } \\
\hline & \multicolumn{2}{|c|}{ Forgone care } & \multirow{2}{*}{$\begin{array}{c}\text { Self-reported barriers } \\
\% \text { of } 15-49 \text { year old women who } \\
\text { self-report problems in accessing } \\
\text { health care }\end{array}$} \\
\hline & $\begin{array}{c}\% \text { of people with a perceived health } \\
\text { care need not seeking appropriate care, } \\
\text { or not at all }\end{array}$ & $\begin{array}{c}\% \text { of children under age } 5 \text { with suspected } \\
\text { pneumonia and/or diarrhea not taken to } \\
\text { an appropriate provider }\end{array}$ & \\
\hline $\begin{array}{l}\text { Availability } \\
\text { (Availability and sufficiency of resources } \\
\text { for delivering comprehensive health } \\
\text { services) }\end{array}$ & $\begin{array}{l}\% \text { Forgoing care due to inadequate } \\
\text { availability of resources }\end{array}$ & Not included & $\begin{array}{l}\% \text { Self-reporting problems due to } \\
\text { inadequate availability of resources }\end{array}$ \\
\hline $\begin{array}{l}\text { Financial accessibility } \\
\text { (Ability to pay for services without } \\
\text { financial hardship) }\end{array}$ & $\begin{array}{l}\% \text { Forgoing care due to financial } \\
\text { reasons }\end{array}$ & Not included & $\begin{array}{l}\% \text { Self-reporting problems due to } \\
\text { financial reasons }\end{array}$ \\
\hline $\begin{array}{l}\text { Contact } \\
\text { (Willingness to contact health services } \\
\text { when they are available, accessible } \\
\text { and acceptable). }\end{array}$ & $\begin{array}{l}\text { \% Forgoing care due to personal } \\
\text { perceptions of illness }\end{array}$ & Not included & \\
\hline $\begin{array}{l}\text { Effective coverage } \\
\text { (Ability to use health services when } \\
\text { needed in a timely manner and at a } \\
\text { level of quality necessary to obtain } \\
\text { desired effect and potential health } \\
\text { gains) }\end{array}$ & $\begin{array}{l}\% \text { Seeking inappropriate health care } \\
\text { (e.g. pharmacy) }\end{array}$ & Not included & \\
\hline
\end{tabular}

a Not included: survey did not collect data on reasons why a caregiver would forgo appropriate health care for a child's illness, spanning the dimensions of access. Source: Prepared by the authors based on reference 20.

those who reported that they did not need care were excluded from the analysis (8).

Last, this study also included information on perceived access barriers among women (Table 2). Values for these indicators were directly obtained from DHS country reports.

\section{Statistical analysis}

For each country, the percentage and confidence intervals were calculated for the indicators presented in Table 2. Prior to estimating the primary outcomes, reported categories of reasons for forgone care were reclassified based on the access barriers dimensions. Expansion factors at the individual level were applied to calculate national totals. When the unweighted number of observations in a specific subgroup was less than 25, results were omitted.

To examine whether percentage values differed by wealth status, quintile rankings were defined according to income or asset-based wealth levels, depending on the data source. For individual-level estimates, household income was adjusted for household size, as described previously (9). The analysis included the cross tabulation of wealth status against all access barriers indicators. Data analyses were conducted using Stata ${ }^{\circledR}$
Statistical Software: Release 15.1 (StataCorp LP, College Station, Texas, United States).

\section{RESULTS}

\section{Forgone care and main barriers: who is left behind?}

The indicators analyzed in this study allowed to measure access barriers using data obtained from household surveys in the Americas. As illustrated using forgone care for perceived health needs in 18 countries with recent LSMS-type or DHS data, the mean percentage of individuals who report forgoing appropriate care during their illnesses or accidents was $29.3 \%(95 \%$ CI $27.4 \%-31.3 \%$ ). There was widespread variation between countries, ranging from $3.1 \%$ to $69.0 \%$ for individuals in the poorest wealth quintiles (Costa Rica and Peru, respectively) and from $2.7 \%$ to $67.5 \%$ for individuals in the wealthiest quintiles (Uruguay and Dominican Republic, respectively) (Figure 1A). In most countries, the percentage of people who reported having foregone needed care was higher among individuals in the poorest wealth quintile than the richest $20 \%$. The largest absolute wealth gap was observed in Nicaragua $(24.1 \%, 95 \%$ CI $24.0 \%-24.2 \%$ ), followed by Guatemala and Colombia with 
FIGURE 1. (A) Forgone care for perceived health needs in countries of the Americas, 2018 (or nearest year). (B) Forgone care for suspected child pneumonia and child diarrhea in countries of the Americas, 2018 (or nearest year)
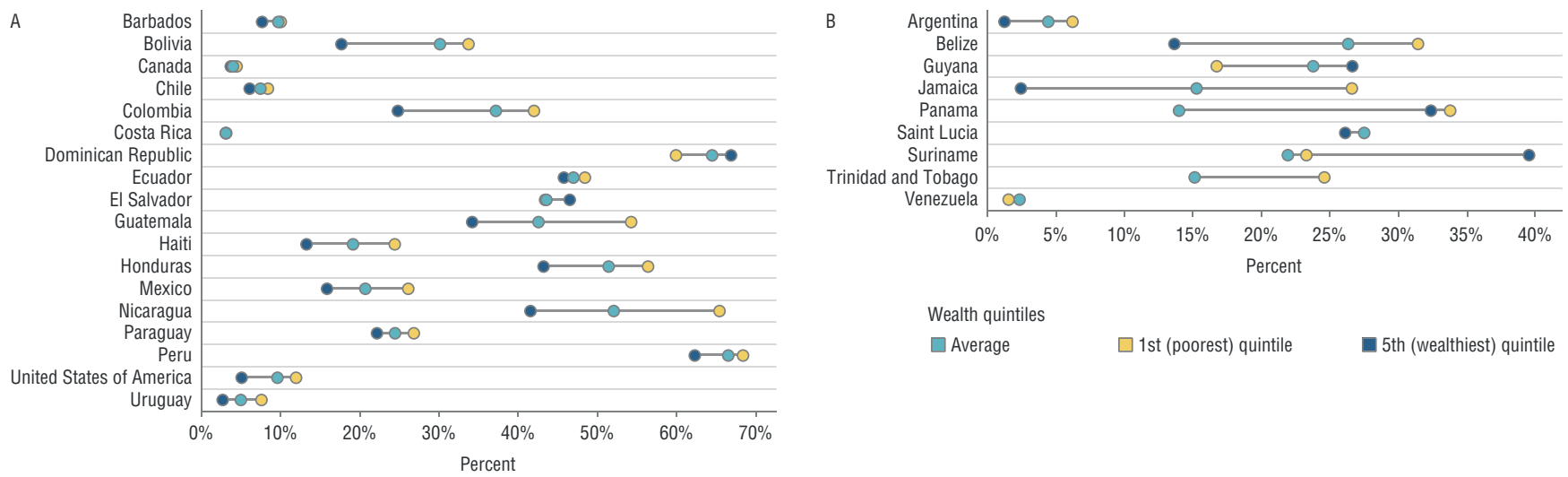

Wealth quintiles

$\square$ Average $\quad \square$ 1st (poorest) quintile $\quad$ 5th (wealthiest) quintile

Note: Includes 13 countries with a household survey based on the Living Standards Measurement Study (LSMS) model, latest survey for each country, 2014-2018; 5 countries with a Demographic Health Survey, latest survey for each country, 2008-2017; and 9 countries with a Multiple Indicators Cluster Survey, latest survey for each country, 2000-2016.

Source: Prepared by the authors from the study results.

FIGURE 2. Distribution of reasons for forgoing appropriate health care in the Americas, countries with available data, 2018 (or nearest year)

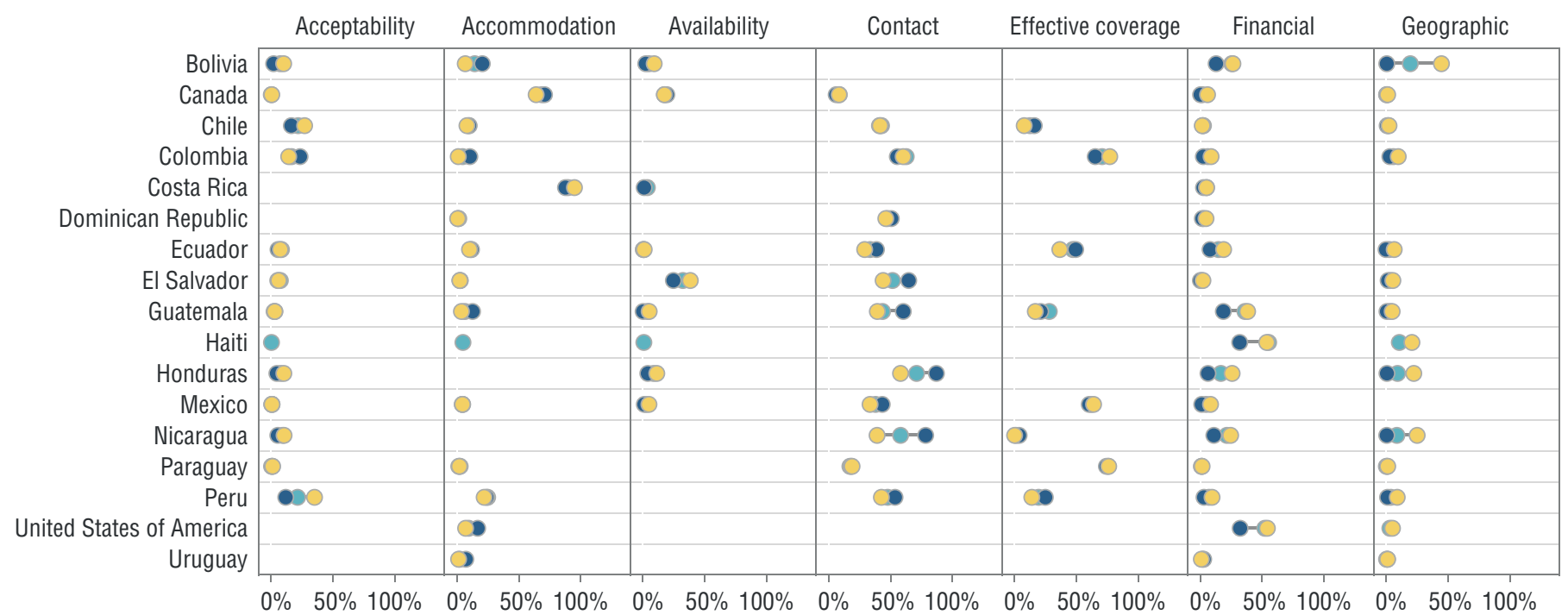

Wealth quintiles

$\square$ 1st (poorest) quintile

5th (wealthiest) quintile

Average

Note: Reasons for forgoing healthcare were classified as Acceptability "does not trust doctors and/or mistreatment of health personnel and/or prefers to be cured with home remedies and/or gender, language and cultural norms inhibit care seeking, Accommodation "ong waiting time and/or lack of time and/or cumbersome administrative requirements, Availability "here are no doctors and/or medicines and/or services at Geographic "Lives far away and/or has no transport:"

Source: Prepared by the authors from the study results.

$20.3 \%$ (95\% CI $18.7 \%-21.9 \%$ ) and $17.4 \%$ (95\% CI $16.2 \%-18.5 \%)$, respectively.

The data also allowed to measure the types and magnitude of access barriers across dimensions of access barriers. Figure 2 presents indicators of reasons for forgone appropriate care for 17 countries, broken down by wealth quintiles and by access barrier dimensions. Because answers categories vary between the surveys studied, the results show variations in indicators and values within each country and across countries. Of the individuals sampled who report forgoing appropriate care, $8.0 \%$ attributed their decision to acceptability issues (95\% CI
$6.7 \%-9.4 \%$ ), while $17.2 \%$ (95\% CI $15.3 \%-19.1 \%$ ) to issues related to accommodation and $15.1 \%$ to financial reasons $(95 \%$ CI $11.5 \%-15.4 \%$ ). Inadequate availability of resources was cited in $8.4 \%$ of episodes $(95 \% \mathrm{CI} 6.3 \%-10.6 \%)$ and geographic access in $5.4 \%$ of cases $(95 \%$ CI $3.8 \%-7.1 \%)$. Unwillingness to seek care due to individuals' perceptions of their illness (contact) was cited in $43.4 \%$ of cases (95\% CI $40.9 \%$ - $46.0 \%$ ), while $39.7 \%$ $(95 \%$ CI $36.8 \%-42.6 \%)$ of individuals sought inappropriate care (e.g., pharmacies) for their illnesses.

Findings show that wealth-based disparities were generally consistent across all access barrier dimensions and countries. In 
FIGURE 3. Women that report having a big problem accessing health care when they are sick, countries with a DHS survey

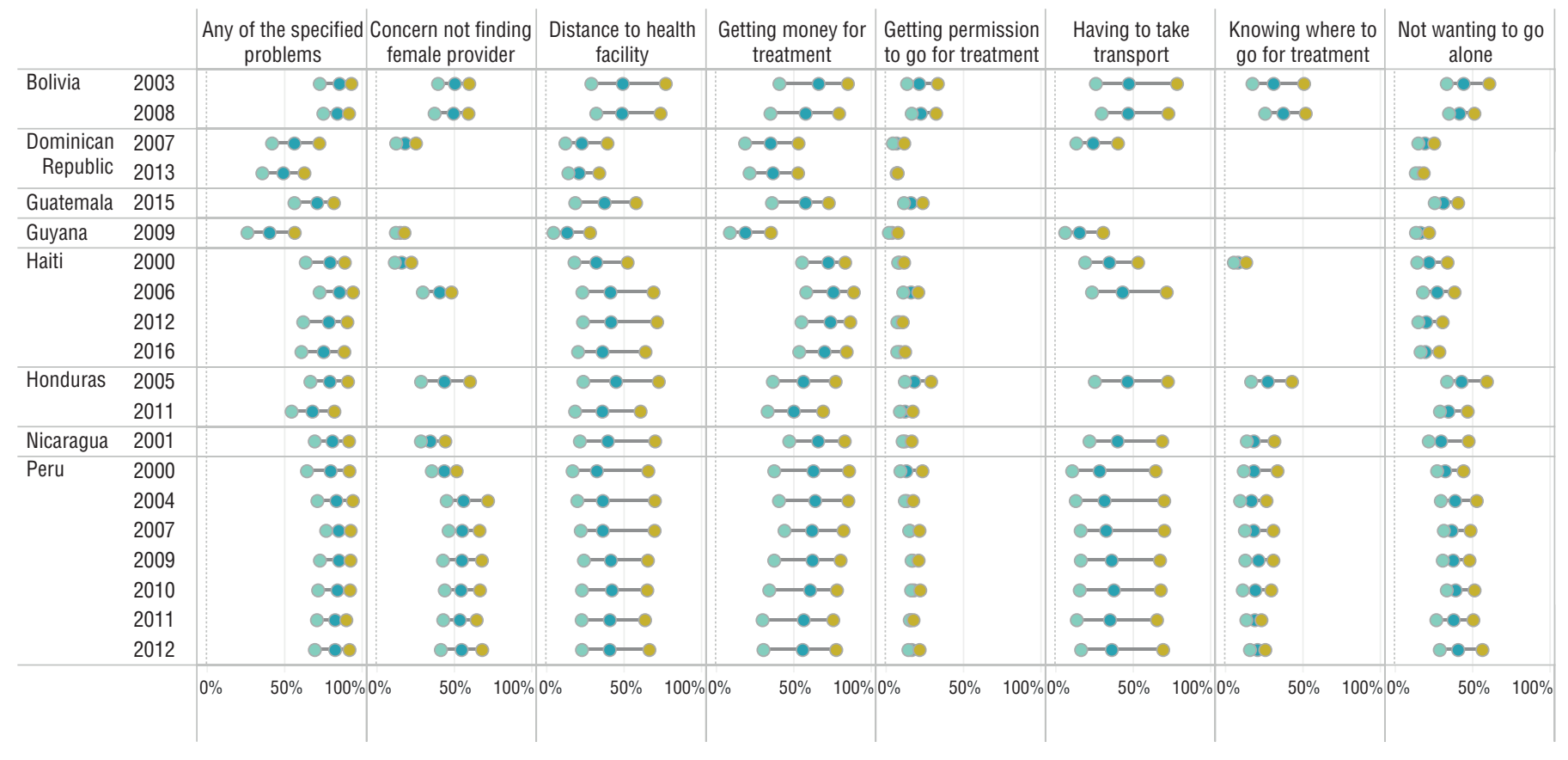

\section{Wealth quintiles}

1st (poorest) quintile $\square$ 5th (wealthiest) quintile $\square$ Average

Source: Prepared by the authors using calculations from country DHS reports.

most countries, people in the poorest wealth quintile were more likely to face multiple barriers than their richer counterparts (Figure 2). Overall, there was higher values among individuals in the poorest quintiles than those in the wealthiest quintiles across all access barrier dimensions except for accommodation, contact, and effective coverage.

Forgone care for common child illnesses (suspected pneumonia and diarrhea). The standard MICS routinely gather information on care seeking for child illness for 20 countries in the Americas. Improving families' care seeking behavior for common child illnesses has been linked to significantly reducing child mortality in developing countries. In this analysis of 9 countries with recent MICS data, the average percentage of mothers / caregivers who report forgoing appropriate care during their child illnesses was 16.9\% (95\% CI 7.4\% - 26.4\%). There was also marked differences between countries, ranging from $2.4 \%$ to $27.8 \%$ (Venezuela and Saint Lucia, respectively). In 5 countries (Argentina, Belize, Jamaica, Panama and Trinidad and Tobago), a higher percentage of mothers / caregivers in the poorest quintile did not seek appropriate care compared to those in the wealthiest quintile (Figure 1B).

Perceived access barriers among women. Figure 3 presents aggregate (national level) and disaggregate (wealth quintile levels) percentages of 15-49 year old women who reported having a big problem accessing health care when they are sick. This indicator was available for 8 countries in DHS reports on perceived access barriers, though with some country-specific variations in the types of included barriers. For example, $87.3 \%$ of Haitian women in the poorest quintile responded that "getting money for treatment" is a serious barrier to accessing care; whereas distance to the health facility represented a significant problem for $76.3 \%$ of Bolivian women in the poorest quintile. In the cases where information is comparable across countries (Bolivia, Nicaragua, and Peru), at least $83.9 \%$ of women reported at least one significant problem in accessing care when sick (with a higher rate of $95.0 \%$ among women in the poorest wealth quintile compared to $72.0 \%$ among women in the richest wealth quintile (Figure 3).

\section{DISCUSSION}

Disparities in barriers to access health services have been documented to vary by country and measures of access, particularly in high income countries (22-24). This study goes further to assess the feasibility to measure access barriers indicators in 26 countries of the Americas based on population surveys and summarize how patterns differ by wealth status and measures of access barriers.

The results of this study show that about one-third of people, on average, experience multiple barriers, including in areas of availability, geographic and financial accessibility, accommodation, acceptability, contact, and effective coverage. Further, population in the poorest wealth quintiles are more likely to experience barriers related to acceptability, financial reasons, inadequate availability of resources and geographic access. In contrast, people in the highest income quintile were more likely to be unwilling to seek care due to individuals' perceptions of their illness (contact) and the accommodation of health services or to seek inappropriate care (e.g., pharmacies) for their illnesses.

Findings regarding magnitude and disparities were consistent with the literature. A previous cross-sectional study based 
on household surveys in 8 LAC countries showed that onethird of people, on average, reported experiencing one or more barriers to seeking appropriate care (ranging from 5\% to $66 \%$ across countries) (18). Reporting of disparities across measures of inequalities in Colombia, El Salvador, Paraguay, and Peru showed that the percentage of individuals that report forgoing appropriate care was consistently higher among the poorest income quintiles in all four countries (19). Another study adapting the Commonwealth Fund International Health Policy Survey to 6 LAC countries showed that around one-third of respondents experienced multiple barriers accessing primary care, associated with cost, scheduling appointments, and long waiting times (16).

Similar to this study, findings from high-income countries demonstrate that people in the lowest income quintile have higher unmet needs (measured through forgone care due to any reason) than the most well-off, although with large variations between countries (25). Two other studies based on the International Health Policy Survey conducted in 11 high-income countries showed that low income was a significant risk factor across most countries for most access barriers measures $(22,26)$. Forgoing care due to cost, difficulties with after-hours primary care, and timely access to primary care appointments are more commonly experienced by people in lower income groups (23, $24,26)$. In one study based on the state-based Behavioral Risk Factor Surveillance System in the United States, the prevalence of unmet health care needs because of cost varied by nearly 28 percentage points by Federal Poverty Level category (ranging from $5.3 \%$ to $32.9 \%$ across FPL categories) (27).

This study suggests that barriers to access do not occur in isolation and may be multifactorial. Indeed, research on the facilitators and obstacles to access health services suggests that personal, health system factors, and social determinants can interact to influence access to care (28). Existing quantitative research in the Americas further demonstrates the coexistence of multiple access barriers faced by people. For example, a couple of cross-sectional studies examining challenges to seeking care for chronic illness in Nicaragua, Honduras, and Guatemala found that appropriate care seeking was associated with location, gender, age, health status, perceived quality of care, household income, and insurance status $(29,30)$.

Another study on access barriers along the care trajectory conducted in Brazil and Colombia revealed the coexistence of geographical and economic barriers and the need for authorization from insurers in Colombia, whereas in Brazil, limited availability of health centers, doctors and drugs that leads to longer waiting times were common barriers (8). Another study focusing on unmet needs in Brazil found that financial reasons, long waiting times and lack of professionals and services were main reasons for forgoing appropriate care (31). Qualitative research further indicates that factors associated with poorer access are interconnected, such that people experiencing multiple vulnerability factors may have even greater barriers to health services, which require coordinated action of multiple sectors beyond health (32-35).

Limitations. In interpreting the information provided in this analysis, some limitations need to be considered. First, the studied measures of access barriers relied on national surveys that limited the choice of access barrier indicators included and the study of access in its broad dominion, that is from seeking health care to achieving good outcomes from that care. The studied indicators can, for example, identify specific reasons why individuals fail to seek care at various points in time, but it is not possible to know the connection between timely receipt of care and desired outcomes. New ways to collect quality data on access barriers need to be developed, including strengthening national health information systems to obtain disaggregated data on access barriers and triangulate qualitative information on users and providers experiences into national monitoring efforts. Related to this complexity is the fact that most household surveys reveal little about the specific health conditions (e.g., noncommunicable diseases) for which access barriers are being faced and target setting is therefore difficult. Exploring these issues will require alternative sources of data, such as facility-based surveys and qualitative information. Further research needs to explore the effects of sociodemographic, economic, and disease-related variables on care seeking behavior during illness or accident.

It is also important to note that the inequality analysis presented in this study was limited. Several factors that can be affecting access barriers inequalities were not addressed-such as gender, ethnicity, and lack of education- which represents an important research gap. Although it is possible to identify general regional patterns, differences were observed in how perceived health needs and related behavior questions were phrased and recorded, whether respondents were asked about the reasons why they reported forgoing appropriate care and recall periods for various questions (the full wording of items for each survey is available from the authors upon request). These differences limited the ability to compare across countries in terms of access barrier indicators and deserve further study as they have implications for efforts to reduce inequalities. The combination of country-year estimates for each indicator further limited the comparability across countries as it is challenging to attribute differences to actual differences in performance rather than differences in survey questions, timing, and data availability. Although this study did not compare countries in terms of performance, issues of multiple comparisons and consistency across instruments were addressed in this study in a descriptive manner by carefully reviewing and categorizing access barriers and deleting irrelevant observations (e.g., those who did not report needing care). Finally, the retrospective nature of the data collected, and its reliability on individuals' perceptions of illness and selfreported treatment seeking patterns can also lead to recall and social desirability biases in reporting of access barrier events that, in turn, affect levels and trends. Future work should support countries in selecting tracer indicators to see how access barriers change over time and by wealth quintiles providing a proxy for comprehensive monitoring of universal health and the SDGs.

\section{CONCLUSIONS}

The results show important variations in incidence values across countries and subpopulation groups within each country, which indicates major inequalities and uneven progress in many access barrier indicators within the Americas.

The results suggest the need for integrated and multisectoral approaches aimed at facilitating access to health services; 
namely, to strengthen the capacity of health systems to meet the health needs of the population and to reduce deterrents to optimal health care seeking identified in this study, such as high cost, insurance problems, lack of time, inadequate availability of resources, and low willingness to seek care due to cultural/ linguistic reasons.

The study identified important challenges of using household surveys data, mainly due to marked heterogeneity in indicators and instruments across countries (e.g., how questions are phrased, whether respondents were asked about the reasons why they did not seek appropriate care, recall periods, and answer categories). These variations make comparability across countries difficult and undermine regional monitoring. This highlights the need to standardize survey instruments and data on access barrier indicators in the Region, including harmonizing questions asked in different assessments and questionnaires, setting standards and benchmarks, and adding missing concepts into questionnaires.
Author contributions. $\mathrm{NH}, \mathrm{EB}$, and ADR participated in the design of the study and interpretation of the results. $\mathrm{EB}$ and $\mathrm{NH}$ conceived the original idea and planned the analysis. NH analyzed the data. Overall direction and planning were overseen by ADR. All authors reviewed and approved the final version.

Funding. This study was financed by the U.S. Government through the U.S. Agency for International Development (USAID) under the PAHO- USAID Umbrella Grant Agreement 2016-2021. The funder had no role in the study design, data collection, analysis and modeling, interpretation of the results, or writing of the manuscript.

\section{Conflicts of interest. None declared.}

Disclaimer. Authors hold sole responsibility for the views expressed in the manuscript, which may not necessarily reflect the opinion or policy of the RPSP/PAJPH and/or PAHO.

\section{REFERENCES}

1. Pan American Health Organization. Strategy for universal access to health and universal health coverage. 53rd Directing Council, 29 September - 3 October 2014; Washington, DC: PAHO; 2014. Available from: http://iris.paho.org/xmlui/handle/123456789/7652 Accessed 16 January 2020.

2. Pan American Health Organization. PHC 30-30-30, PAHO's new Regional Compact on Primary Health Care for Universal Health. Washington, DC: PAHO; 2017.

3. Pan American Health Organization. Compendium of Outcome Indicators - PAHO Strategic Plan 2020-2025. Washington, DC: PAHO; 2019. Available from: https://www.paho.org/hq/index. php?option $=$ com_docman\&view $=$ download \&alias $=50465$ strategic-plan-of-the-pan-american-health-organization-20202025-compendium-of-outcome-indicators\&category_slug= planning-budget-9000\&Itemid=270\&lang=en Accessed 12 February 2020.

4. United Nations. Transforming our world: the 2030 agenda for sustainable development. $70^{\text {th }}$ Session of the United Nations General Assembly, 21 October 2015; New York: UN; 2019. Available from: http://www.un.org/en/ga/search/view_doc.asp?symbol=A/ RES/70/1 Accessed 12 March 2020.

5. Institute of Medicine (US). Committee on Monitoring Access to Personal Health Care Services: Access to Health Care in America. Washington (DC): National Academies Press (US); 1993. Available from: https: / / www.ncbi.nlm.nih.gov/books/NBK235891/ Accessed 13 January 2020.

6. Boerma T, AbouZahr C, Evans D, Evans T. Monitoring Intervention Coverage in the Context of Universal Health Coverage. PLoS Med. 2014; 11(9):e1001728. doi:10.1371/journal.pmed.1001728.

7. Richard L, Furler J, Densley K, Haggerty J, Russell G, Levesque J-F, et al. Equity of access to primary healthcare for vulnerable populations: the IMPACT international online survey of innovations. Int J Equity Health. 2016;15:64.

8. Garcia-Subirats I, Vargas I, Mogollón-Pérez AS, De Paepe P, da Silva MRF, Unger JP, et al. Barriers in access to healthcare in countries with different health systems. A cross-sectional study in municipalities of central Colombia and north-eastern Brazil. Soc Sci Med. 2014; 106:204-13.

9. Souza EC, Vilar RL, Rocha NS, Ochoa AC, Rocha PM. Primary health care access and receptivity to users: an analysis of perceptions by users and health professionals. Cad Saude Publica. 2008; (24):S100-10.

10. Vargas I, Vázquez ML, Mogollón AS, Unger JP. Barriers of access to care in a managed competition model: lessons from Colombia. BMC Health Serv Res. 2010;10: 297.
11. Cunha AB, Vieira da Silva LM. Health services accessibility in a city of Northeast Brazil Cad Saude Publica. 2010; 26(4):725-37.

12. Abadia CE, Oviedo DG. Bureaucratic itineraries in Colombia. A theoretical and methodological tool to assess managed-care health care systems. Soc Sci Med. 2009; 68 (6):1153-60.

13. Santos-Fernandes NF, Galvão JR, Araújo-Assis MM, de Almeida $\mathrm{PF}$, Dos Santos AM. Access to uterine cervical cytology in a health region: invisible women and vulnerable bodies. Cad Saúde Pública. 2019;35(10):e00234618.

14. Irons R. Qualitative analysis of the care in the family planning services offered quechua-speaking patients in Ayacucho, Peru. Rev Peru Med Exp Salud Publica. 2019; 36(2):188-95.

15. Guanais F, Regalia F, Perez-Cuevas R, Anaya M. From the patient's perspective: experiences with primary health care in Latin America and the Caribbean. Washington, DC: Inter-American Development Bank; 2019. Available from: https://publications.iadb.org/ publications/english/document/From-the-Patients-PerspectiveExperiences-with-Primary-Health-Care-in-Latin-America-andthe-Caribbean.pdf Accessed 20 May 2020.

16. Macinko J, Guanais FC, Mullachery P, Jimenez G. Gaps in primary care and health system performance in six Latin American and Caribbean countries. Health Affairs. 2016; 35(8): 1513-21.

17. Primary Health Care Performance Initiative. PCHCPI Core Indicators. Available from: https://improvingphc.org/phcpi-coreindicators Accessed 17 January 2020.

18. Báscolo E, Houghton N, Del Riego A. Lógicas de transformación de los sistemas de salud en América Latina y resultado en acceso y cobertura de salud. Rev Panam Salud Publica. 2018;42:e126. https://doi. org/10.26633/RPSP.2018.126.

19. Houghton N, Bascolo E, del Riego A. Socioeconomic inequalities in access barriers to seeking health services in four Latin American countries. Rev Panam Salud Publica. 2020; 44:e11. https://doi. org/10.26633/RPSP.2020.11

20. HoughtonN, BascoloE, del Riego A. Monitoring access barriers to health services in the Americas: a mapping of household surveys. Rev Panam Salud Publica. 2020;44:e96. https://doi.org/10.26633/PSP.2020.96.

21. Báscolo E, Houghton N, Riego A del. Construcción de un marco de monitoreo para la salud universal. Rev Panam Salud Pública. 2018;42:e81.

22. Corscadden L, Levesque JF, Lewis V, Strumpf E, Breton M, Russell G. Factors associated with multiple barriers to access to primary care: an international analysis. Int J Equity Health. 2018;17(2). doi:10.1186/s12939-018-0740-1

23. Davis K, Ballreich J. Equitable access to care--how the United States ranks internationally. N Engl J Med. 2014; 371(17):1567-70. 
24. De Looper M, Lafortune G. Measuring disparities in health status and in access and use of health care in OECD countries. Paris: OECD Publishing, 2009. Available from: https://doi. org/10.1787/225748084267 Accessed 20 May 2020.

25. Organization for Economic Cooperation and Development. Unmet needs for health care: comparing approaches and results from international surveys. Paris: OECD; 2020. Available from http://www. oecd.org/health/health-systems/Unmet-Needs-for-Health-CareBrief-2020.pdf Accessed 8 June 2020.

26. Schoen C, Osborn R, Squires D, Doty MM, Pierson R, Applebaum $\mathrm{S}$. How health insurance design affects access to care and costs, by income, in eleven countries. Health Aff. 2010; 29(12):2323-34.

27. Okoro CA, Zhao G, Fox JB, Eke PI, Greenlund KJ, Town M. Surveillance for health care access and health services use, adults aged 18-64 years - Behavioral Risk Factor Surveillance System, United States, 2014. MMWR Surveill Summ. 2017; 66(7):1-42.

28. Carrillo JE, Carrillo VA, Perez HR, Salas-Lopez D, Natale-Pereira A, Byron AT. Defining and targeting health care access barriers. J Health Care Poor Underserved. 2011; 22(2):562-75.

29. Emmerick IC, Luiza VL, Camacho LA, Vialle-Valentin C, RossDegnan D. Barriers in household access to medicines for chronic conditions in three Latin American countries. Int J Equity Health. 2015; 14:115. doi:10.1186/s12939-015-0254-z.

30. Acuña C, Marin N, Mendoza A, Emmerick ICM, Luiza VL, Azeredo TB. Determinantes sociales de la exclusión a los servicios de salud y a medicamentos en tres países de América Central. Rev Panam Salud Publica. 2014; 35:128-35.
31. Osorio RG, Servo LM, Piola SF. Unmet health care needs in Brazil: an investigation about the reasons for not seeking health care. Cien Saude Colet. 2011; 16(9): 3741-54.

32. Hirmas Adauy M, Poffald Angulo L, Jasmen Sepúlveda AM, Aguilera Sanhueza X, Delgado Becerra I, Vega Morales J. Barreras y facilitadores de acceso a la atención de salud: una revisión sistemática cualitativa. Rev Panam Salud Pública. 2013; 33:223-9.

33. Collins JH, Bowie D, Shannon G. A descriptive analysis of health practices, barriers to healthcare and the unmet need for cervical cancer screening in the Lower Napo River region of the Peruvian Amazon. Womens Health (Lond). 2019;15. doi:10.1177/1745506519890969.

34. Malacarne J, Gava C, Escobar AL, Souza-Santos R, Basta PC. Health service access for tuberculosis diagnosis and treatment among indigenous peoples in Rondônia state, Brazilian Amazon, 2009-2011: a cross-sectional study. Epidemiol Serv Saúde. 2019; 28(3): e2018231.

35. Coimbra Júnior CE, Santos RV, Welch JR, Cardoso JR, Souza $\mathrm{MC}$, Garnelo L, et al. The first national survey of indigenous people's health and nutrition in Brazil: rationale, methodology, and overview of results. BMC Public Health. 2013;13:52. doi: 10.1186/1471-2458-13-52.

Manuscript received on 15 April 2020. Revised version accepted for publication on 2 June 2020.

\section{Medición de las barreras al acceso a los servicios de salud en las Américas a través de datos de las encuestas de hogares}

RESUMEN Objetivos. Determinar las ventajas y los problemas de la utilización de datos de las encuestas de hogares para medir las barreras al acceso a los servicios de salud en las Américas, e informar los resultados de las encuestas más recientes.

Métodos. Estudio descriptivo transversal que empleó datos de encuestas de hogares representativas a nivel nacional y disponibles públicamente, realizadas en 27 países de las Américas. Se generaron valores para los indicadores de las barreras al acceso a la búsqueda de servicios de salud utilizando los conjuntos de datos e informes disponibles de los países. Los resultados se desagregaron por quintiles de riqueza según ingreso o niveles de riqueza basado en activos.

Resultados. La mayoría de las encuestas fueron similares en cuanto al enfoque general y a las categorías de su contenido. Sin embargo, los cuestionarios específicos eran diferentes para cada país, lo que dificultó las comparaciones entre ellos. En promedio, alrededor de un tercio de las personas experimentaron múltiples barreras para acceder una atención sanitaria adecuada. Hubo gran variabilidad entre los países en cuanto a la experiencia de esas barreras, aunque las disparidades fueron relativamente constantes entre los países. Las personas del quintil de riqueza más desfavorecido tuvieron más probabilidades de experimentar barreras en lo que respecta a la aceptabilidad, la accesibilidad geográfica y financiera y la disponibilidad de recursos. Conclusiones. Existen grandes desigualdades basadas en la situación de riqueza y un progreso desigual para superar las múltiples barreras al acceso que obstaculizan el avance hacia los objetivos de equidad que forman parte de los Objetivos de Desarrollo Sostenible y de la salud universal en las Américas. Las barreras al acceso son múltiples, lo que pone de relieve la necesidad de adoptar enfoques integrados y multisectoriales para enfrentarlas. La variabilidad de los instrumentos empleados en los distintos países sugiere que en el futuro es necesario estandarizar los cuestionarios y mejorar la calidad y la disponibilidad de los datos para la vigilancia regional de las barreras al acceso.

Palabras clave Accesibilidad a los servicios de salud; cobertura universal de salud; desarrollo sostenible; Américas. 